ХАРАКТЕРИСТИКА ГРУППЫ ПОВЫШЕННОГО РИСКА ЗАБОЛЕВАНИЯ ТУБЕРКУЛЕЗОМ СРЕДИ ВОЕННОСЛУЖАЩИХ И ОПРЕДЕЛЕНИЕ ПУТЕЙ ДАЛЬНЕЙШЕГО СОВЕРШЕНСТВОВАНИЯ ПРОТИВОТУБЕРКУЛЕЗНЫХ МЕРОПРИЯТИЙ В ВООРУЖЕННЫХ СИЛАХ РОССИЙСКОЙ ФЕДЕРАЦИИ

Р. Д. Мучаидзе ${ }^{1}$, В. В. Данцев ${ }^{1}$, Р. В. Безносик ${ }^{2}$, В. К. Гришин ${ }^{2}$ Ю. Н. Шитов ${ }^{1}$, М. Г. Спицын

${ }^{1}$ ФГБВОУ ВО «Военно-медицинская академия имени С. М. Кирова» МО РФ, г. Санкт-Петербург, Россия

2 Филиал № 2 ФГКУ «Главный военный клинический госпиталь имени Н. Н. Бурденко» МО РФ, г. Пушкино, Московская область, Россия

\title{
CHARACTERISTICS OF THE TUBERCULOSIS RISK GROUP AMONG MILITARY SERVICEMEN AND DETERMINATION OF THE PATHS FOR THE FURTHER IMPROVEMENT OF ANTI-TUBERCULOSIS MEASURES IN THE ARMED FORCES
}

\section{OF THE RUSSIAN FEDERATION}

R. D. Muchaidze ${ }^{1}$, V. V. Dantsev ${ }^{1}$, R. V. Beznosik ${ }^{2}$, V. K. Grishin ${ }^{2}$, Yu. N. Shitov ${ }^{1}$, M. G. Spitsyn ${ }^{1}$

${ }^{1}$ S. M. Kirov Military Medical Academy the Russian Defense Ministry, Saint Petersburg, Russia 
${ }^{2}$ Branch № 2 of the N. N. Burdenko Main Military Clinical Hospital, Pushkino, Moscow region, Russia

Резюме. Представлен результат анализа заболеваемости туберкулезом военнослужащих в 2009-2015 гг. Установлены наиболее значимые факторы риска и вклад группы риска в заболеваемость в современных условиях. Оценено качество диспансерного наблюдения за группой риска, выявлены основные недостатки. Предложены пути дальнейшего совершенствования противотуберкулезных мероприятий в Вооруженных силах Российской Федерации: проведение иммунодиагностики туберкулеза у граждан перед началом военной службы и углубленное медицинское обследование всего молодого пополнения войск (библ.: 11 ист.).

Ключевые слова: военнослужащие, Вооруженные силы, риск, туберкулез.

Статья поступила в редакичи 02.05.2017 2. 
Summary. The result of analysis of the tuberculosis morbidity of military servicemen in 2009-2015 is presented. The most significant risk factors and the contribution of risk group in the morbidity in modern conditions are established. Quality of the dispensary observation of risk group is estimated, the principal defects are revealed. The paths for the further improvement of anti-tuberculosis measures in the Armed Forces of the Russian Federation are offered: carrying out the immunodiagnostics of tuberculosis at citizens before the beginning of military service and profound medical examination of all young army reinforcement (bibliography: 11 refs).

Key words: Armed Forces, military servicemen, risk, tuberculosis.

Article received 02.05.17. 
Одним из приоритетных направлений борьбы с туберкулезом являются профилактические мероприятия в группе повышенного риска заболевания туберкулезом. В медицине под термином «группа риска» традиционно понимается часть населения, условно объединенная по принципу повышенной вероятности возникновения в ней каких-либо заболеваний и других нарушений здоровья. Общеизвестно, что имеются группы лиц, предрасположенные к туберкулезу. Выделение этих групп важно, так как позволяет сосредоточить основное внимание здравоохранения на сравнительно небольшой части населения для организации активного раннего выявления больных и проведения профилактических мероприятий по предупреждению болезни. Это отмечено в материалах 67-й сессии Всемирной ассамблеи здравоохранения (ВОЗ) (2014 г.) и других документах ВО3 [1-4].

Предрасположенность к туберкулезу связана с различными факторами медицинского, биологического (генетического) и социального характера. К медицинским факторам риска относят: контакт с источниками туберкулезной инфекции, инфицирование и перенесенный ранее туберкулез, наличие остаточных посттуберкулезных изменений в органах дыхания, ВИЧ-инфекцию, психические расстройства, алкоголизм, нарко- и токсикоманию, хронические заболевания органов дыхания, желудочно-кишечного тракта, мочеполовой системы, сахарный диабет, онкогематологические заболевания, длительное лечение кортикостероидными гормонами, противоопухолевыми препаратами и иммунодепрессантами, лучевую терапию, беременность, роды и аборты у женщин и т. д. Наличие биологической (генетической) предрасположенности эмпирически можно предполагать у лиц, чьи родственники больны (или ранее болели) туберкулезом, даже если они не находятся в семейном контакте. К социальным факторам относят: содержание в местах лишения свободы (следственных изоляторах, исправительных учреждениях) или профессиональный контакт с контингентом подследственных и осужденных 
(пенитенциарный фактор риска), социально дезадаптированное поведение, отсутствие работы, жилья, принадлежность к мигрантам, беженцам и переселенцам, проживание в приютах, ночлежках, интернатах для престарелых, интенсивные, длительные или частые стрессы, переутомление, десинхроноз, плохое питание, материальное и семейно-бытовое неблагополучие и т. д.

Известно, что заболеваемость туберкулезом лиц с остаточными посттуберкулезными изменениями в органах дыхания в 5-13 раз выше заболеваемости взрослого населения. Заболеваемость лиц, инфицированных возбудителем туберкулеза, в 5-10 раз выше, чем неинфицированных. Лица с гиперергическими реакциями на туберкулиновую пробу Манту заболевают туберкулезом в 8-10 раз чаще лиц, имеющих нормергические реакции. Заболеваемость контингентов пенитенциарных учреждений в 15-20 раз, а лиц, контактировавших с больными туберкулезом, в 5-7 раз выше заболеваемости населения в целом [5-7].

В нашей стране ряд групп повышенного риска заболевания туберкулезом определен официально в законодательных и нормативных актах, других руководящих и методических документах.

Военная служба предъявляет высокие требования к состоянию здоровья граждан. Поэтому многие факторы риска заболевания туберкулезом, важные для гражданского здравоохранения, в условиях военной службы не играют существенной роли. Например, пациенты с ВИЧ-инфекцией, злокачественными новообразованиями, болезнями крови и кроветворных органов, иммунными нарушениями, сахарным диабетом, психическими расстройствами и многими другими заболеваниями негодны (или ограниченно годны) к военной службе, особенно - по призыву. Некоторые же факторы риска, напротив, являются особо актуальными, так как их наличие не ограничивает годность граждан к военной службе. 
Современная система организации противотуберкулезных мероприятий в Вооруженных силах $(\mathrm{BC})$ основана на разработанной в 80-х гг. прошлого века начальником кафедры фтизиатрии Военно-медицинской академии имени С. М. Кирова (ВМедА) В. В. Рыбалко модели заболеваемости туберкулезом военнослужащих [8]. Моделирование позволило определить заболеваемость в зависимости от чувствительности к туберкулину и различных признаков зараженности, а также удельный вес и структуру группы повышенного риска среди молодого пополнения и больных военнослужащих.

Факторы риска, наиболее актуальные для молодого пополнения:

- перенесенный до начала военной службы туберкулез (после излечения и снятия с диспансерного учета фтизиатра по месту жительства); 
- гиперергическая реакция на туберкулиновую пробу Манту с 2 TE;

- контакт с больным туберкулезом до начала военной службы;

- наличие остаточных посттуберкулезных изменений в органах дыхания у так называемых рентгеноположительных лиц.

По данным моделирования, в период военной службы заболеваемость туберкулезом лиц, перенесших болезнь до начала службы, в 13,3 раза выше общей заболеваемости военнослужащих; «гиперреакторов» по пробе Манту — в 11 раз; лиц, имевших контакт с больным туберкулезом до начала службы, — в 6,8 раза; рентгеноположительных лиц — в 5,2 раза выше соответственно. Заболеваемость всей группы риска в целом в 10,3 раза выше заболеваемости военнослужащих, не вошедших в группу риска, особенно в первые 6 мес службы. Лица из группы риска составили около $40 \%$ заболевших. Таким образом, профилактическая работа с группой риска только из числа молодого пополнения позволяет рассчитывать на существенное (почти в 2 раза) снижение заболеваемости военнослужащих туберкулезом.

Кроме того, для военнослужащих важными факторами риска явились:

- контакт с больным туберкулезом в период военной службы (казарменный, семейный, квартирный и т. д.);

- перенесенный в период военной службы по контракту туберкулез (после излечения и снятия с диспансерного учета фтизиатра по месту службы).

Со времени данного исследования эпидемиологическая ситуация по туберкулезу в мире и в нашей стране претерпела значительные изменения. Так же существенно мог варьировать и состав группы повышенного риска среди военнослужащих. Возможно, что отдельные факторы риска утратили свою актуальность, а другие - стали более значимыми. Поэтому изучение 
структуры группы риска заболевания туберкулезом среди военнослужащих в современных условиях имеет большое практическое значение не только для врачей-фтизиатров, но и для всей военно-медицинской службы.

\section{ЦЕЛЬ}

Установление наиболее значимых в настоящее время факторов риска заболевания туберкулезом у военнослужащих и совершенствование противотуберкулезных мероприятий в ВС РФ на основе ретроспективного анализа заболеваемости.

\section{МАТЕРИАЛЫ И МЕТОДЫ}

Проведен ретроспективный анализ историй болезни военнослужащих, лечившихся по поводу туберкулеза в военно-медицинских организациях Министерства обороны Российской Федерации (МО РФ) в 2009-2015 гг. Использованы данные Всеармейского регистра больных туберкулезом (филиал № 2 Главного военного клинического госпиталя (ГВКГ) имени им. Н. Н. Бурденко). Непосредственное изучение больных и их медицинской документации проводилось в 11 военных госпиталях. Общее число больных туберкулезом, включенных в исследование, - 2611, из них военнослужащих по призыву - 1430 (54,8\%), военнослужащих по контракту - 1181 (45,2\%). Проанализированы сроки военной службы больных туберкулезом, пути выявления и структура клинических форм заболевания, основные факторы риска у больных, а также качество диспансеризации военнослужащих из группы риска. 


\section{РЕЗУЛЬТАТЫ И ОБСУЖДЕНИЕ}

Для оценки происхождения туберкулеза у военнослужащих изучено распределение больных по срокам их военной службы. У 24,1\% больных военнослужащих по призыву (практически - у каждого четвертого) заболевание выявлено в первый месяц военной службы. В военной фтизиатрии такие случаи расцениваются как «проникший» туберкулез, т. е. заболевание, развившееся до начала военной службы, но не распознанное при освидетельствовании граждан. Это наглядно подтверждает важность углубленного медицинского обследования молодого пополнения в войсках. На 2-6-м мес службы по призыву туберкулез выявлен у $35,8 \%$ больных. Согласно модели В. В. Рыбалко, чаще всего именно в эти сроки (в период адаптации к новым условиям военной службы) заболевают молодые военнослужащие из группы повышенного риска (происходит «взрыв эндогенного туберкулеза») [8]. Во втором полугодии службы по призыву заболевание выявлено у 38\% больных. Этот период, в свою очередь, характеризуется повышенной заболеваемостью лиц, которые заразились уже в период службы от ранее заболевших сослуживцев. Доля больных второго года военной службы по призыву незначима $(2,1 \%)$.

Большинство больных военнослужащих по контракту $(89,8 \%)$ имеют срок службы свыше 1 года. Доля прослуживших 7-12 мес - 6,2\%, 2-6 мес-3,2\%. Доля «проникшего» туберкулеза незнач ма $(0,8 \%)$, хотя военным фтизиатрам известен ряд случаев «проникновения» на службу по контракту больных тяжелыми и эпидемически опасными формами туберкулеза легких с распадом легочной ткани и бактериовыделением. Следует отметить, что в настоящее время в руководящих документах не предусмотрено углубленное медицинское 
обследование в войсках молодого пополнения граждан, поступающих на службу по контракту, по аналогии с молодым пополнением по призыву. Если это обследование станет обязательным, следует ожидать роста доли «проникшего» туберкулеза и у них. Кроме того, врачи воинских частей получат возможность своевременно брать под диспансерное динамическое наблюдение молодых военнослужащих по контракту с повышенным риском заболевания туберкулезом и проводить им химиопрофилактику.

Пути выявления туберкулеза у военнослужащих характеризуют его своевременность и тем самым в значительной степени определяют прогноз эпидемиологической ситуации в войсках.

Из числа больных военнослужащих по призыву 36,9\% выявлены при плановой флюорографии, 12,9 - при лечении в госпитале по поводу нетуберкулезных заболеваний, 1,5 - при обследовании контактных лиц в очаге, 0,5\% - при обследовании лиц, находящихся на диспансерном учете в группе риска. В нашей стране (в том числе в ВС) перечисленные пути выявления принято относить к активным и ранним, позволяющим охватить обследованием независимо от наличия или отсутствия признаков заболевания бо́льшую часть населения (личного состава). Это помогает обнаружить болезнь на относительно ранних стадиях, с ограниченными по протяженности процессами, незначительными клиническими симптомами или полным их отсутствием, a также представляющих меньшую эпидемиологическую опасность для окружающих. Суммарная доля путей активного выявления туберкулеза у военнослужащих по призыву составила $51,8 \%$, что явно недостаточно. В Российской Федерации в целом за 2011-2014 гг. аналогичный показатель по результатам профилактических осмотров населения составил не менее 60\% [7]. Большинство же больных военнослужащих по призыву $(48,2 \%)$ были выявлены пассивно при обращении за медицинской помощью с симптомами туберкулеза. 
Среди военнослужащих по контракту ситуация более благоприятна. Большинство больных (49,4\%) выявлены при плановой флюорографии, $8 \%$ при лечении в госпитале по поводу нетуберкулезных заболеваний, $2 \%$ - при обследовании контактных лиц в очаге, 1\% - при обследовании лиц, находящихся на диспансерном учете в группе риска. Суммарная доля путей активного выявления туберкулеза составила $60,4 \%$.

Структура клинических форм туберкулеза у военнослужащих наглядно отражает качество профилактической работы, своевременность выявления заболевания и характеризует эпидемиологическую ситуацию в целом. Так, преобладание «свежих» форм вторичного туберкулеза с преимущественно продуктивным типом воспаления, небольших по протяженности (очаговый, ограниченный инфильтративный, туберкулема) и без распада легочной ткани говорит о своевременном выявлении больных, эффективности профилактики и эпидемиологическом благополучии (на территории, в войсках и т. д.).

В обеих группах военнослужащих на первом месте среди клинических форм туберкулеза органов дыхания инфильтративный туберкулез (52,7 и $52,5 \%)$. На втором месте - очаговый туберкулез (27,7 и 23,8\%). На третьем месте у военнослужащих по призыву - туберкулезный плеврит $(11,2 \%)$, по контракту - туберкулема (11,6\%). Доля туберкулем у военнослужащих по призыву - 4,9\%, а доля плеврита у военнослужащих по контракту - 3,2\%. Диссеминированный туберкулез у военнослужащих по призыву $-2,1 \%$, по контракту — 6,7\%. Доля «классических» форм первичного туберкулеза и других клинических форм невелика (менее 1\%).

Таким образом, в обеих группах военнослужащих преобладают формы вторичного туберкулеза (более 85\%). Доля инфильтративного туберкулеза значительно выше доли очагового (у военнослужащих по призыву — в 1,9 раза, по контракту — в 2,2 раза), что может быть связано с несвоевременным выявлением части больных, а также острым течении заболевания. 
В патогенезе туберкулеза у военнослужащих закономерно сочетаются механизмы эндогенной реактивации и экзогенной инфекции. Как правило, в первые 6 мес службы абсолютно преобладает эндогенная реактивация, а в дальнейшем - экзогенная инфекция [8]. Современная эпидемиологическая ситуация по туберкулезу в ВС, обусловленная развитием заболевания преимущественно у ранее инфицированных лиц, определяет комплекс необходимых профилактических мероприятий, которые прежде всего направлены на военнослужащих из группы повышенного риска.

По результатам проведенного исследования различные факторы риска были выявлены у 528 военнослужащих по призыву и 320 военнослужащих по контракту. Удельный вес группы риска в общей заболеваемости туберкулезом составил: у военнослужащих по призыву - 36,9\%; у военнослужащих по контракту $-27,1 \%$.

Наиболее значимыми факторами риска оказались:

- контакт с больным туберкулезом до начала военной службы: первое место у военнослужащих по призыву (54\%), третье - у военнослужащих по контракту (14,4\%);

- контакт с больным туберкулезом в период военной службы: первое место у военнослужащих по контракту $(54,1 \%)$, второе - у военнослужащих по призыву (24,6\%); 
- наличие остаточных посттуберкулезных изменений в органах дыхания: второе место у военнослужащих по контракту $(22,2 \%)$, третье - у военнослужащих по призыву (10,6\%).

По степени эпидемиологической значимости к контакту с больным туберкулезом следует приравнивать содержание в местах лишения свободы, а также профессиональный контакт с подследственными и осужденными лиц молодого пополнения до начала службы и военнослужащих в период службы [9].

Удельный вес столь важного фактора риска, как перенесенный до начала службы туберкулез, оказался незначителен $(3,6 \%$ у военнослужащих по призыву и 5\% - у военнослужащих по контракту), возможно, за счет отсева таких граждан при освидетельствовании в военных комиссариатах. Единичные рецидивы туберкулеза, перенесенного в период военной службы $(1,5 \%)$, отмечены только у военнослужащих по контракту (военнослужащие по призыву после лечения подлежат увольнению с военной службы).

Удельный вес гиперергической реакции на туберкулиновую пробу Манту также незначителен $(7,2 \%$ у военнослужащих по призыву и $2,8 \%$ - у военнослужащих по контракту), так как массовая туберкулинодиагностика в войсках была отменена в 2012 г. Однако это не снижает значения гиперергии на туберкулин как важного фактора риска [4]. В настоящее время кроме пробы Манту возможно применение внутрикожной пробы с аллергеном туберкулезным рекомбинантным в стандартном разведении. В этом случае в группу повышенного риска заболевания туберкулезом следует относить лиц с положительной реакцией на данную пробу (при наличии папулы любого размера или осложненной реакции). В соответствии с принятыми в нашей стране правилами эта иммунологическая проба должна выполняться всем гражданам до 18 лет ежегодно. В условиях относительно благоприятной эпидемиологической ситуации по туберкулезу обнаружение и превентивное 
лечение лиц с латентной инфекцией приобретает все большее значение, поэтому вопрос об иммунодиагностике туберкулеза у военнослужащих в настоящее время актуален [10]. Следует отметить, что в западных странах туберкулинодиагностика и другие иммунологические тесты успешно применяются для обследования на туберкулез лиц с высоким риском заболевания, в том числе кандидатов на военную службу [11].

По нашему мнению, иммунодиагностика туберкулеза (туберкулиновая проба Манту или проба с аллергеном туберкулезным рекомбинантным в стандартном разведении) должна стать обязательным диагностическим исследованием для граждан, подлежащих призыву на военную службу, поступающих на службу по контракту и поступающих в военно-учебные заведения. По направлению военных комиссариатов это исследование целесообразно выполнять в противотуберкулезных диспансерах до начала освидетельствования для определения годности к военной службе (если оно не проводилось или если в медицинских документах отсутствуют сведения о данном исследовании в течение последних 6 мес). Результат пробы должен быть зафиксирован в картах медицинского освидетельствования граждан. Это позволит войсковым врачам при углубленном медицинском обследовании молодого пополнения выявлять лиц с гиперергической реакцией на туберкулин, положительной реакцией на пробу с аллергеном туберкулезным рекомбинантным и включать их в группу повышенного риска заболевания туберкулезом. Кроме того, военные фтизиатры и эпидемиологи получат возможность оценивать инфицированность молодого пополнения и прогнозировать эпидемиологическую ситуацию по туберкулезу в войсках.

В сохранении здоровья военнослужащих, имеющих повышенный риск заболевания туберкулезом, важную роль играют мероприятия диспансерного динамического наблюдения и химиопрофилактика. Анализ полученных данных показал, что качество диспансеризации группы риска в настоящее время 
недостаточное. Из числа больных туберкулезом, имевших различные факторы риска, эти факторы не были выявлены у 93\% военнослужащих по призыву и около 89\% военнослужащих по контракту. Данные лица не состояли на диспансерном учете врача части в группе риска, не получали химиопрофилактику, поэтому предотвратить у них туберкулез не удалось. В отдельных случаях у лиц из группы риска имели место отказы (уклонение) от химиопрофилактики и отсутствие медицинского контроля над приемом химиопрофилактических препаратов, a также недооценка (пропуск) рентгенологами на флюорограммах малых остаточных посттуберкулезных изменений, обнаруживаемых у больных туберкулезом ретроспективно.

\section{ЗАКЛЮЧЕНИЕ}

Профилактическая работа военно-медицинской службы с группой повышенного риска заболевания туберкулезом среди военнослужащих остается актуальным и приоритетным направлением в комплексе противотуберкулезных мероприятий в войсках. Ее совершенствование не требует проведения дорогостоящих диагностических исследований. Необходима иммунодиагностика туберкулеза у граждан перед началом военной службы. Углубленное медицинское обследование молодого пополнения в войсках должно быть обязательным для всех категорий военнослужащих. Качественное проведение этой работы позволит рассчитывать на дальнейшее снижение заболеваемости туберкулезом в Вооруженных силах Российской Федерации. 


\section{СПИСОК ЛИТЕРАТУРЫ / REFERENCES}

1. World Health Organization. Sixty-Seventh World Health Assembly. Geneva, 1924 May 2014. Resolutions and decisions. Annexes. Geneva; 2014.

2. World Health Organization. Systematic screening for active tuberculosis: principles and recommendations. Geneva; 2013.

3. World Health Organization. Systematic screening for active tuberculosis: an operational guide. Geneva; 2015.

4. World Health Organization. Guidelines on the management of latent tuberculosis infection. Geneva; 2015.

5. Mitinskaya L. A. Tuberculinodiagnostics (lecture). Problemy tuberkulyesa. 1998;

3: 76-7. Russian (Митинская Л. А. Туберкулинодиагностика (лекция). Проблемы туберкулеза. 1998; 3: 76-7).

6. Shilova M. V. Tuberculosis in Russia in 2012-2013. Moscow; 2014. Russian (Шилова М. В. Туберкулез в России в 2012-2013 гг. М.; 2014).

7. Tuberculosis in the Russian Federation, 2012/2013/2014. Analytical review of statistical indicators used in the Russian Federation and in the world. Moscow; 2015. Russian (Туберкулез в Российской Федерации, 2012/2013/2014 гг. Аналитический обзор статистических показателей, исполь- зуемых в Российской Федерации и в мире. М.; 2015).

8. Rybalko $V$. V. State and prospects of military phthisiology. Assembly speech on december 29th 1991 in the day of 193th anniversary of academy. Saint Petrsburg: VMedA; 1991. Russian (Рыбалко В. В. Состояние и перспективы военной фтизиатрии. Актовая речь 29 декабря 1991 года в день 193-й годовщины академии. СПб.: ВМедА; 1991).

9. Muchaidze R. D., Shitov Yu. N., Dantsev V. V. Penitantiary tuberculosis risk factor of military servicemen. Infektsiya i immunitet. 2012; 2 (1-2): 43-4. 
Russian (Мучаидзе Р. Д., Шитов Ю. Н., Данцев В. В. Пенитенциарный фактор риска заболевания туберкулезом военнослужащих. Инфекция и иммунитет. 2012; 2 (1-2): 43-4).

10. Dantsev V. V., Karpushchenko V. G., Bolekhan V. N., Muchaidze R. D., Ivanov $V$. V., Shitov Yu. N., Spitsyn M. G. The directions of preventive work perfection in the military servicemen with increased risk of tuberculosis. Vestn. Ros. voen.med. akad. 2016; 3 (55): 99-104. Russian (Данцев В. В., Карпущеенко В. Г., Болехан В. Н., Мучаидзе Р. Д., Иванов В. В., Шитов Ю. Н., Спицын М. Г. Направления совершенство- вания профилактической работы в группе военнослужащих с повышенным риском заболевания туберкулезом. Вестн. Рос. воен.-мед. акад. 2016; 3 (55): 99-104).

11. Mancuso J. D., Tobler S. K., Keep L. W. Pseudoepidemics of tuberculin skin test conversions in the U. S. Army after recent deployments. Am. J. Respir. Crit. Care Med. 2008; 177: 1285-9. 



\section{ИНФОРМАЦИЯ ОБ АВТОРАХ}

Мучаидзе Рубен Девильевич - ассистент кафедры фтизиатрии, ФГБВОУ ВО «Военно-медицинская академия имени С. М. Кирова» МО РФ, 194044, Россия, г. Санкт-Петербург, ул. Академика Лебедева, д. 6, конт. тел.: +7(911)9703879, e-mail:rmuchaidze@yandex.ru

Данщев Владимир Викторович - докт. мед. наук, заведующий кафедрой фтизиатрии, ФГБВОУ ВО «Военно-меди- цинская академия имени С. М. Кирова» МО РФ, 194044, Россия, г. Санкт-Петербург, ул. Академика Лебедева, д. 6, конт. тел.: +7(911)8357696, e-mail: vladimirdancev@ yandex.ru

Безносик Роман Валентинович - канд. мед. наук, начальник филиала — главный фтизиатр МО РФ, филиал

№ 2 ФГКУ «Главный военный клинический госпиталь имени Н. Н. Бурденко» МО РФ, 141206, Россия, Московская обл., г. Пушкино, ул. Лесная, д. 67

Гришин Владимир Кузьмич - заведующий диспансерным кабинетом, филиал № 2 ФГКУ «Главный военный клинический госпиталь имени Н. Н. Бурденко» МО РФ, 141206, Россия, Московская обл., г. Пушкино, ул. Лесная, д. 67

Шитов Юрий Николаевич - доцент кафедры фтизиатрии, ФГБВОУ ВО «Военно-медицинская академия имени С. М. Кирова» МО РФ, 194044 , Россия, г. Санкт-Петербург, ул. Академика Лебедева, д. 6 
Спицын Михаил Геннадьевич - канд. мед. наук, доцент кафедры фтизиатрии, ФГБВОУ ВО «Военно-медицинская академия имени С. М. Кирова» МО РФ, 194044, Россия, г. Санкт-Петербург, ул. Академика Лебедева, д. 6 


\section{INFORMATION ABOUT AUTHORS}

Muchaidze Ruben D. - Assistant of the Phthisiology Department, S. M. Kirov Military Medical Academy the Russian Defense Ministry, 6, Akademika Lebedeva str., Saint Petersburg, Russia, 194044, cont. phone: +7(911)9703879, email: rmuchaidze@yandex.ru

Dantsev Vladimir V. - D. Sc. (Medicine), the Head of the Phthisiology Department, S. M. Kirov Military Medical Academy the Russian Defense Ministry, 6, Akademika Lebedeva str., Saint Petersburg, Russia, 194044, cont. phone: +7(911)8357696, e-mail: vladimirdancev@yandex.ru

Beznosik Roman V. - Ph. D. (Medicine), the Chief of the Branch - Chief phthisiologist of the Ministry of Defence of the Russian Federation, Branch № 2 of the N. N. Burdenko Main Military Clinical Hospital, 67, Lesnaya str., Pushkino, Moscow region, Russia, 141206

Grishin Vladimir K. - Ph. D. (Medicine), the Head of the Dispensary Cabinet, Branch № 2 of the N. N. Burdenko Main Military Clinical Hospital, 67, Lesnaya str., Pushkino, Moscow region, Russia, 141206

Shitov Yury N. - Associate professor of the Phthisiology Department, S. M. Kirov Military Medical Academy the Russian Defense Ministry, 6, Akademika Lebedeva str., Saint Petersburg, Russia, 194044

Spitsyn Mikhail G. - Ph. D. (Medicine), Associate professor of the Phthisiology Department, S. M. Kirov Military Medical Academy the Russian Defense Ministry, 6, Akademika Lebedeva str., Saint Petersburg, Russia, 194044 